\title{
LA COMICIDAD COMO PERJUICIO DE SUJETOS INTENCIONALES
}

\author{
Manuel Pérez Otero \\ Universidad de Barcelona \\ Facultad de Filosofía \\ Departamento de Filosofía \\ LOGOS (Research Group in Analytic Philosophy) \\ perez.otero@ub.edu
}

RESUMEN: En este artículo presento, clarifico y exploro algunas virtudes potenciales de una determinada teoría — de carácter intencionalista - sobre lo cómico. Su tesis mínima principal establece una condición necesaria para la comicidad: quien evalúaaprecia una situación como humorística/cómica reconoce un perjuicio o daño ocasionado a ciertos sujetos intencionales (pueden ser sujetos involucrados en la situación cómica, o el propio evaluador-apreciador). Una versión más fuerte establece que la comicidad deriva (al menos en parte) de dicho perjuicio. El perjuicio es aquello que, cuando se combina con otros factores, encontramos humorístico/cómico. Clarificar la teoría conlleva una tarea de comparación con otras concepciones del humor, en particular, con la teoría de la incongruencia.

PALABRAS CLAVE: humor, divertimento, teoría de la incongruencia, metachistes, J. Morreall

SUMMARY: In this article, I present, clarify and explore some potential virtues of a particular theory —of an intentional character- about comicity. Its principal minimal thesis posits a necessary condition for comicity: the thinker who appraises a situation as comic recognizes a hurt or damage against certain intentional subjects (they may be subjects involved in the comic situation, or the appraiser himself). A stronger version claims that comicity proceeds (partially, at least) from that hurt; it is the hurt itself that, when combined with other factors, we find comic. The task of clarifying the theory involves to compare it with other views on humor, in particular the incongruity theory.

KEY WORDS: humor, amusement, incongruity theory, meta-jokes, J. Morreall

\section{Introducción}

En 1951, D.H. Monro presentó una clasificación de las principales concepciones filosóficas sobre el humor propuestas a lo largo de la historia, y las dividió en cuatro categorías: teorías de la superioridad, teorías de la incongruencia, teorías del alivio [relief, release from restraint] y teorías de la ambivalencia (cfr. Monro 1951). En estudios 
posteriores, otros autores suelen hacer referencia a las tres primeras. ${ }^{l}$ Por lo general, se considera que las teorías de la superioridad y las teorías del alivio son bastante problemáticas. La teoría (o las teorías) de la incongruencia aparece como el enfoque más prometedor, y muchos especialistas han defendido - en épocas relativamente recientes - versiones de esa concepción.

Usaré los conceptos de comicidad y de humor con los sentidos en que son equivalentes. Voy a presentar, clarificar y explorar algunas virtudes potenciales de una determinada teoría - de carácter intencionalista - sobre lo cómico. Este enfoque también podría considerarse una versión o variante de la teoría de la incongruencia, pero creo que arroja nueva luz sobre algunos aspectos de la comicidad en torno a los cuales la teoría de la incongruencia no es suficientemente clarificadora.

Mi teoría establece sólo una condición necesaria de la comicidad; no intenta proponer condiciones necesarias y conjuntamente suficientes, ni siquiera condiciones suficientes. Casi todas las teorías previas aspiran a caracterizar el humor (lo cual implica ofrecer condiciones necesarias y conjuntamente suficientes de lo humorístico), pero se les plantean contraejemplos que las ponen en duda, sobre todo, contraejemplos a su pretensión de establecer condiciones suficientes del humor.

En rigor, propondré dos teorías: una versión débil y una fuerte de una misma idea genérica. Expresada de forma muy laxa e imprecisa, esa idea es la siguiente: la comicidad concierne al perjuicio o daño de sujetos intencionales. La versión débil establece que quien evalúa-aprecia una situación como humorística/cómica reconoce un perjuicio o daño ocasionado a ciertos sujetos intencionales (pueden ser sujetos involucrados en la situación cómica, o el propio evaluadorapreciador). La versión fuerte afirma, además, que la comicidad deriva (al menos en parte) de dicho perjuicio; es el perjuicio aquello que, cuando se combina con otros factores, encontramos humorístico/cómico.

En la sección 2 hago una presentación de esa teoría del perjuicio, algunas de cuyas consecuencias importantes se exponen en la sección 3. Más adelante constato cómo otros enfoques (la teoría de la superioridad y ciertas versiones de la teoría de la incongruencia) son problemáticos al pretender proponer condiciones suficientes del humor (sección 4). Sin embargo, hay conexiones entre la teoría del per-

${ }^{1}$ Cfr., por ejemplo, Clark 1970; Morreall 1983, 1987 (Introducción), 2009 (cap. 1); Carroll 2014 (cap. 1). 
juicio y esas otras dos concepciones (teoría de la superioridad y teoría de la incongruencia), que describo en la sección 5. La sección 6 ilustra la teoría del perjuicio utilizando como ejemplos ciertos chistes y metachistes.

\section{Comicidad como perjuicio: preliminares}

Evaluamos o apreciamos como humorísticas entidades de categorías ontológicas diversas y con diferentes niveles de complejidad: novelas, obras teatrales, películas, frases, chistes, gags, personas, dibujos, rostros, sucesos, gestos, etc. Aunque aquí no tematizaré este punto, supondré que el carácter cómico de algunas de esas entidades se vincula con la comicidad de ingredientes suyos comparativamente más elementales o básicos (escenas, secuencias, sketches, pasajes, gags, diálogos,...), y muy probablemente depende de ellos. A fin de facilitar la exposición, hablaré de "situaciones" para referirme a esas unidades cómicas, sean o no componentes de entidades cómicas de mayor complejidad. Es un uso algo laxo y técnico del término, pues debe englobar chistes, gags, frases, dibujos y otros elementos cómicos que no es frecuente catalogar como situaciones.

Con frecuencia, en una situación cómica intervienen o están involucrados sujetos intencionales, o de una u otra forma se alude a ellos; sean reales o imaginarios, sean concretos o "genéricos" (colectivos de personas con algún rasgo común: los borrachos, los varones, las mujeres, los homosexuales, los avaros, quienes practican determinada profesión, los calvos, quienes padecen cierta minusvalía psíquica, los individuos de tal o cual raza o nación, entre otros). Denominaré a esos sujetos "protagonistas cómicos" (o, simplemente, "protagonistas"). Conviene prestar atención a otro sujeto intencional relevante cuando analizamos el humor, al cual podemos llamar "el apreciador". La literatura filosófica contemporánea suele abordar lo humorístico rastreando sus conexiones con la respuesta característica que tiende a provocar: el estado mental de divertimento o regocijo cómico [comic amusement $].^{2}$ El concepto de divertimento, o de regocijo, abarca casos desconectados de la comicidad, en los cuales nos regocijamos por otras causas. Pero, según una práctica terminológica habitual (con respecto a "amusement"), mientras no indique lo contrario hablaré aquí de divertimento o regocijo en un sentido restringido, para referirme sólo al divertimento humorístico, provocado por situaciones cómicas ( $c f r$. Clark 1970, p. 142; Martin 1983, p. 173). La persona

${ }^{2}$ Cfr., por ejemplo, Clark 1970, p. 142; Scruton 1982, p. 157; Morreall 1983, p. 39; 1987, Introducción; 2009, cap. 3; Carroll 2014, pp. 4-5. 
que experimenta ese divertimento es el apreciador, quien aprecia o siente algo como cómico. (También podríamos catalogarlo como "evaluador", porque evalúa la situación como cómica. Pero esta otra noción tiene connotaciones intelectualistas que - en principio- prefiero evitar.)

Disponemos ya de los conceptos básicos para hacer una presentación, preliminar, de la teoría intencionalista sobre el humor que quiero explorar. En las secciones subsiguientes se clarificarán sus rasgos principales, conforme avance la discusión.

La idea central, vertebradora del presente enfoque, podría formularse así: un rasgo esencial de la comicidad es que concierne al perjuicio o daño de sujetos intencionales. A continuación aparece una versión débil de esa teoría del perjuicio:

TDP: cuando un apreciador experimenta divertimento cómico ante una situación, reconoce o detecta un perjuicio en sujetos intencionales.

La teoría, en su versión fuerte, establece además lo siguiente:

TFP: TDP es el caso y la comicidad que provoca el divertimento deriva (al menos en parte) de dicho perjuicio; ese perjuicio es aquello que, cuando se combina con otros factores, el apreciador encuentra cómico.

La primera clarificación que hace falta atañe al concepto de perjuicio. Aunque los diccionarios contemplan la posibilidad de que haya perjuicio contra entidades inanimadas (y pasa algo similar respecto de los conceptos casi equivalentes de daño, deterioro, menoscabo o lesión), probablemente cuando hay perjuicio contra una de esas entidades (por lo común, artefactos u otros objetos que puedan resultar útiles a sujetos intencionales), el perjuicio repercute — quizá de forma muy indirecta - en los intereses de sujetos intencionales. Por ello, tal vez sea innecesario hablar de perjuicio o daño de sujetos intencionales; sin embargo, no estoy seguro de si es correcta esa consideración, y he preferido hacer explícito - a riesgo de resultar redundanteque el perjuicio aquí tematizado concierne a tales sujetos.

En todo caso, el sentido apropiado de perjuicio es muy amplio. Pensemos en la extraordinaria diversidad de modos en que cabe perjudicar a un individuo, o a un colectivo. Para empezar, toda suerte de agresión física constituye un caso de perjuicio; también lo es el daño infligido contra posesiones del individuo, incluso a cualesquier objetos que pudieran sernos útiles. Por otro lado, cada vez que un estado 
intencional (un deseo, una creencia, una expectativa, una aspiración, o cualquier otro, en relación con cualquier tema) resulta — de una $\mathrm{u}$ otra forma - no satisfecho, ello redunda en perjuicio del sujeto correspondiente. También el orgullo, la dignidad, la honorabilidad pueden ser lesionados. El perjuicio puede ser, asimismo, un estado o condición permanente del sujeto. Por último, el perjuicio no tiene por qué revestir especial gravedad, un perjuicio insignificante también es un perjuicio (este punto es importante; volveremos sobre él después).

\section{Situaciones cómicas, apreciadores y bodegones}

Ilustraré ciertas consecuencias relevantes de la teoría del perjuicio recién esbozada. Supongamos que $S C_{1}$ es una situación que, aparentemente, cumple las dos condiciones siguientes:

(i) $S C_{1}$ es una situación cómica, con potencial para provocar divertimento en al menos un apreciador $A$;

(ii) no hay protagonistas cómicos perjudicados en $S C_{1}: S C_{1}$ no involucra sujetos intencionales, o bien, aunque los involucra, no tiene lugar perjuicio alguno contra ellos.

La teoría, tanto en su versión débil, TDP, como en su versión fuerte, TFP, permite hacer frente a potenciales contraejemplos de ese tipo. Lo comprobaremos con mayor detalle en secciones subsiguientes. Pero veamos ahora, aunque sea en abstracto y de forma muy general, las estrategias naturales que protegen la teoría ante esos problemas.

Ocupémonos, primero, de la versión débil. Incluso si $S C_{1}$ es una situación que satisface, en efecto, las condiciones (i) y (ii), eso es compatible con la TDP si el perjuicio reconocido por el apreciador, $A$, no es de sujetos intencionales de $S C_{1}$. ¿Qué otros sujetos podrían ser? Hay una situación más amplia, $S C_{2}$, que incluye a $S C_{1}$ como parte propia; es la situación en que $S C_{1}$ es presentada ante $A$ y $A$ aprecia o evalúa dicha situación, $S C_{1}$. Examinemos, pongamos por caso, qué sucede cuando se cuenta un chiste. La situación comunicativa incluye al emisor, $E$, y a una audiencia, $A$, formada por uno o varios sujetos intencionales. (No veo inconveniente en simbolizar del mismo modo, con la letra $A$, a la audiencia y al apreciador, pues asumo que es esa audiencia la destinada a apreciar-evaluar el chiste; el emisor pretende provocar divertimento cómico en la audiencia.) Esa situación comunicativa, que también incluye la situación $S C_{1}$ "contada" en el chiste, es una situación, $S C_{2}$, en la cual según la TDP — salvo que 
hubiera otra candidata mejor a constituir una situación con los rasgos postulados por la TDP - hay perjuicio de sujetos intencionales: los estados intencionales de $A$ son frustrados en alguna medida. Por ejemplo, algunos autores sostienen que la sorpresa en la audiencia es esencial al chiste, en el sentido de que el chiste, como acto de habla, quedaría frustrado sin ella ( $c f r$. Vigara Tauste 1994, p. 81). ${ }^{3}$ Si fuera así, habrá expectativas de $A$ que resulten insatisfechas. Naturalmente, si nos gusta que nos cuenten chistes esperamos que el divertimento provocado contrarreste esa frustración de expectativas, cuyo carácter lesivo suele ser minúsculo (ya he indicado que el perjuicio de lo cómico puede ser insignificante). En general, también las sorpresas positivas acarrean cierto nivel de frustración de estados doxásticos (de otro modo, no serían sorpresas). (Sin embargo, en la sección 7 examinaremos chistes en los cuales el perjuicio del apreciador no deriva sólo de esa mera sorpresa.)

Generalicemos para cubrir todas las situaciones cómicas, no sólo los chistes. Según la TDP, el divertimento cómico del apreciador, $A$, se correlaciona con un reconocimiento o detección por parte de $A$ de algún perjuicio en sujetos intencionales. Cuando la situación $S C_{1}$ tiene los rasgos (i) y (ii), el sujeto intencional perjudicado (así reconocido o detectado por $A$ ) es él mismo, el apreciador. (Veremos después que, en tales casos, el perjuicio no siempre será, o no será sólo, la frustración de expectativas de $A$.) Definamos una situación cómica desnuda como aquella que no incluye al apreciador de la misma. Como estamos señalando, no se infringe la TDP aunque existan situaciones cómicas desnudas con el rasgo (ii), es decir, sin sujetos intencionales perjudicados. Pero para una situación así, $S C_{1}$, habrá una situación más amplia, $S C_{2}$, que incluye $S C_{1}$ y al apreciador, $A$. Quizá $S C_{1}$ no involucre sujetos intencionales perjudicados, pero $S C_{2}$ — conforme a la TDP — sí lo incluye. Para la verdad de la TDP, basta el perjuicio de $A$ reconocido por éste.

Vayamos ahora con la versión fuerte de la teoría, TFP. Asumiendo un supuesto casi trivial, o terminológico (a saber, la situación cómica es aquello que el apreciador encuentra cómico; la comicidad reside en la situación cómica), la TFP implica que no existen situaciones cómicas desnudas con el rasgo (ii). Dicho con otras palabras: si una

${ }^{3}$ Carroll (2014, pp. 17-18) rechaza ese vínculo entre el chiste y la sorpresa, y propone contraejemplos en los cuales un chiste no se cuenta por primera vez. Muchos chistes, en efecto, continúan regocijándonos aunque los hayamos oído con anterioridad. Pero comprender un chiste es, paradigmáticamente, comprender el efecto cómico que provocaría en quien nunca lo ha oído. Por ello, quizá exista un vínculo esencial entre chistes y sorpresa, como postula Vigara Tauste. 
situación, $S C_{1}$, no incluye ningún apreciador ni tampoco sujetos intencionales perjudicados, entonces $S C_{1}$ no es una situación cómica. ¿Cómo reaccionar ante cualquier presunto contraejemplo? Desde la perspectiva de la TFP, puede responderse así: una situación $S C_{1}$, sin apreciador ni sujetos intencionales perjudicados, sólo resultará cómica en apariencia. La situación cómica conectada de manera relevante con $S C_{1}$ será una situación más general, $S C_{2}$, que sí incluye al apreciador, así como algún perjuicio para él detectado por él mismo y que provoca su divertimento.

Resaltar un contraste entre el valor artístico y la comicidad según la concibe la TFP contribuirá a comprender mejor esta última. Una teoría (suficientemente) general del arte debería decir algo sobre los papeles que - en relación con una obra de arte - desempeñan dos sujetos intencionales: el autor de la obra y el apreciador de la misma. Sin embargo, eso no implica que una teoría así esté necesariamente comprometida con suponer que uno y otro sujetos intencionales sean ingredientes esenciales de la obra de arte estrictamente considerada, de la obra desnuda, poseedora de un valor artístico. En otros términos: hay al menos un sentido bastante natural conforme al cual ciertas pinturas, por ejemplo, un bodegón —o un paisaje - donde no aparecen representados seres humanos, pueden estar dotadas de valor artístico sin contener sujetos intencionales (o, cuando menos, eso pueden proponer legítimamente muchas teorías estéticas). Pues bien, la TFP rechaza la posibilidad de algo análogo respecto del valor cómico. La comicidad contiene sujetos intencionales, a los cuales se ocasiona algún perjuicio. Si un "bodegón cómico" es una situación cómica carente de sujetos intencionales, la TFP establece - si queremos sintetizarlo con un eslogan - que no existen tales bodegones cómicos. ${ }^{4}$

\section{Condiciones presuntamente suficientes de lo cómico}

Tanto la versión débil como la versión fuerte de la teoría del perjuicio establecen sólo condiciones necesarias acerca de la comicidad. No proponen condiciones que sean al tiempo necesarias y suficientes (por lo tanto, no proponen una caracterización o definición de lo cómico),

\footnotetext{
${ }^{4}$ Según Scruton (1982, p. 167), sólo provoca divertimento lo humano, o lo que contemplamos como humano desde una perspectiva antropomórfica. En efecto, puede haber humor en un bodegón sin figuras humanas si los objetos se presentan apropiadamente antropomorfizados (como en una película de Disney). A mi juicio, su intuición básica es correcta, aunque yo generalizaría, para incluir sujetos intencionales cualesquiera (cuyos casos paradigmáticos, por supuesto, son los humanos).
} 
ni siquiera proponen condiciones suficientes. La TDP establece una condición relativa al estado mental que lo cómico tiende a provocar, el divertimento; señala que el divertimento en el apreciador es correlativo al reconocimiento de algún perjuicio. La TFP añade que la comicidad reside, al menos en parte, en dicho perjuicio; el perjuicio, combinado con otros factores, es lo que provoca el divertimento. Las palabras en cursivas indican que tampoco la TFP define el humor; sólo establece una condición necesaria; esos otros factores (sobre los cuales no se investigará en este artículo) serían los que permitirían completar la TFP para obtener una caracterización.

La tentación de pensar que la teoría del perjuicio tiene muchos y claros contraejemplos puede proceder de fuentes diversas. Una de ellas es ignorar el rasgo que estoy resaltando: la teoría no aspira a definir lo cómico. Consideraciones del tipo "el humor no consiste en el perjuicio de la gente" y "eso no es lo que (nos) provoca divertimento" manifiestan esa confusión. La TFP no establece que el humor consista sólo en eso, ni que eso por sí mismo baste para provocar(nos) divertimento.

Aunque descubrir y esclarecer las condiciones necesarias del humor ya sea una tarea iluminadora, buscamos - por lo común- mayor iluminación; querríamos caracterizar el fenómeno. Será instructivo preguntarnos por algunas otras teorías que — según se suelen interpretar - aspiran a ello. Comentaré muy brevemente la teoría de la superioridad y ciertas versiones de la teoría de la incongruencia.

La teoría de la superioridad tiene precursores en Platón, Aristóteles y Descartes, pero su principal representante es Hobbes. Según este enfoque, nuestra risa expresa un sentimiento de superioridad respecto a personas que, conforme a nuestra perspectiva, sufren algún tipo de infortunio; establecemos —en relación con algún aspectouna comparación entre nosotros y esas personas (que, en la versión de Hobbes, podemos ser nosotros mismos en una etapa anterior), y nos vanagloriamos de la diferencia. Contra esa teoría se alega la existencia de contraejemplos en los dos sentidos: el divertimento cómico o la risa no siempre van acompañados de tales sentimientos de superioridad; por otro lado, la presunta superioridad en cuestión puede estar desconectada por completo de lo cómico. ${ }^{5}$

La idea principal de las teorías de la incongruencia es que el divertimento es resultado del reconocimiento o la percepción de falta

${ }^{5}$ Cfr., por ejemplo, las críticas de Hutcheson (1750) a Hobbes recogidas en Morreall 1987 (pp. 26-40); cfr. también Monro 1951, caps. 8, 9; Morreall 1983, cap. 2; Carroll 2014, cap. 1. 
de congruencia entre dos elementos; por ejemplo, un elemento puede ser algo real (o presentarse como real conforme a alguna ficción) y el otro puede derivar de patrones generales sobre lo que se espera o se desea que hubiera ocurrido, patrones originados a partir de reglas o regularidades de muy diversa índole: normas sociales, leyes naturales, reglamentos, expectativas, máximas que regirían la comunicación racional exitosa - en el sentido recogido por Grice 1975-, etc. ${ }^{6}$ También los dos elementos incongruentes entre sí pueden pertenecer a uno de esos dos ámbitos; es decir, ser ambos reales (o presentarse como tales), o ejemplificar patrones generales contrapuestos. Hay rasgos de esa concepción en Kant, Schopenhauer y Bergson. En el último medio siglo, encontramos versiones sofisticadas de esa misma concepción en Clark 1970, Martin 1983, Raskin 1984, Morreall 2009 o Carroll 2014. ${ }^{7}$

Consideremos la viabilidad de las teorías de la incongruencia. Para que la relación de incongruencia manejada resulte verosímil como condición necesaria de la comicidad, se requiere un sentido bastante laxo del concepto de incongruencia ( $f f r$., por ejemplo, la discusión en Scruton 1982). Eso no me parece objetable. Sin embargo, dicha laxitud repercute negativamente en la pretensión de erigirse también en una condición suficiente. Clark (1970, pp. 140-141) y Carroll (2014, pp. 28-29), entre otros, se hacen eco de críticas a esa pretensión, surgidas ya - al menos - desde el siglo XIX. Destacan los casos en que una incongruencia, además de no resultar cómica, tiene efectos negativos ante quien la reconoce o detecta, y le provoca, entre otros, dolor, ira, tristeza, miedo o ansiedad. En su reelaboración de la teoría de la incongruencia, Carroll (2014, pp. 34, 37, 50) propone una cláusula negativa, destinada a descartar explícitamente tales casos. Sin embargo, esa cláusula no descarta contraejemplos neutros, por así decirlo. Llamemos ZAPATOS al caso siguiente: entramos en una sala, allí vemos una caja de zapatos y un par de zapatos demasiado grandes para caber en la caja. ${ }^{8}$ Aunque constituye una situación

${ }^{6}$ Conviene señalar que el marco griceano permite postular otras máximas conversacionales además de las identificadas por Grice, y que la teoría de Grice sobre la significación no literal, en toda su generalidad, concierne a implicaturas en un sentido muy amplio, no restringido a las implicaturas conversacionales (si bien Grice se ocupa prioritariamente de éstas). Sobre este punto, cfr. Pérez Otero 2009 (secciones $3-5)$.

${ }^{7}$ Sobre la frustración de expectativas naturales en fragmentos musicales cómicos (incluso cuando la música está desprovista de trama narrativa), cfr. Casablancas Domingo 2000.

${ }^{8}$ Usaré versalitas para representar (además de tesis concretas) casos específicos, situaciones o chistes, que sirvan como ilustraciones de tesis. 
de incongruencia, ZAPATOS — sin más aditamentos- no despierta divertimento, pero tampoco ninguna de esas emociones negativas.

Se evita una mayor variedad de contraejemplos a la versión simple de la teoría de la incongruencia (incluido el caso ZAPATOS) si se combina la presencia de incongruencia con una condición adicional, restrictiva, sobre la manera de disfrutar ante dicha incongruencia. Según Clark (1970, pp. 150-151), el divertimento cómico es el disfrute de lo (que se percibe o considera) incongruente, al menos hasta cierto punto porque se ve como incongruente; la aparente incongruencia resulta cómica cuando se disfruta por sí misma, como tal incongruencia, no por ninguna otra razón. (Carroll 2014, pp. 37 y 50, incluye una condición similar en su definición, lo cual le permitiría prescindir de su clausula sobre ausencia de efectos negativos de lo incongruente. Cfr. también Scruton 1982, p. 170.)

La idea de disfrutar algo como fin en sí mismo, y no como instrumento de otra cosa, suele emplearse también para describir el carácter de nuestra experiencia al apreciar obras de arte, o el carácter de nuestras vivencias cuando participamos en un juego. Pero precisamente porque algunas obras artísticas representan incongruencias sin resultar cómicas, Martin (1983, p. 176) critica la definición de Clark, alegando que - entre otros contraejemplos - hay casos de deleite estético no cómico en los cuales se disfruta de una incongruencia por sí misma; menciona como ejemplo las figuras del Guernica de Picasso.

También resulta problemática, a mi juicio, la definición de Raskin (1984, cap. 4), emparentada con la teoría de la incongruencia, y por la misma razón general: propone una condición suficiente de lo cómico a la que se plantean contraejemplos. En principio, su tema es el humor; pero luego se restringe a los chistes, para finalmente ocuparse sólo de los chistes con juegos de palabras [verbal jokes]. Identifica lo cómico con lo que es compatible, quizá en parte, con dos "guiones" [scripts] contrapuestos. Quizá esa idea (cercana a la de incongruencia) pueda ser una condición necesaria del humor. Pero el ejemplo BANCO, aseverar "Mi primo está en el banco", contradice que sea una condición suficiente, pues según la definión de Raskin BANCO debería ser cómico. ${ }^{9}$

\footnotetext{
${ }^{9}$ Raskin (1984, p. 132) prevé ocuparse -indirectamente- de presuntos contraejemplos a la suficiencia de su definición en la sección 9 del capítulo 4. Pero sólo encontramos una explicación (en las pp. 145-146) de por qué si los hechos narrados con ambigüedad en un determinado chiste se narran de otra forma, detallando el sentido preciso de cada frase, el resultado ya no es algo cómico (porque esta segunda
} 
La discusión principal en esta sección sugiere que las reelaboraciones de la teoría de la incongruencia defendidas por autores como Clark, Raskin y Carroll son problemáticas porque pretenden definir lo cómico, pero sus respectivas definiciones no proporcionan -aparentemente - condiciones suficientes para la comicidad. (No parece que la teoría de la superioridad esté en mejor situación.)

\section{Incongruencia, malicia, desapego}

Como indica John Morreall — quizá el filósofo que se ha ocupado de teorizar sobre el humor con mayor intensidad y dedicación-, las tres concepciones principales que los filósofos han sostenido tradicionalmente (teorías de la superioridad, de la incongruencia y del alivio) no son incompatibles entre sí. Por ejemplo, las propuestas de David Hartley (1705-1757) contienen elementos de cada uno de esos tres enfoques ( $c f r$. Morreall 1987, p. 41). De hecho, los diferentes autores ni siquiera coinciden en su objeto de estudio: antes del siglo XX se buscaban, preferentemente, las causas psicológicas de la risa y el divertimento; en la actualidad se prioriza no tanto la identificación de explicaciones causales como el análisis conceptual de la risa, el divertimento y el humor ( $c f r$. Morreall 2009, cap. 1).

Pues bien, la TDP y la TFP son también compatibles con aspectos concretos de esas otras teorías. En esta sección señalaré que la teoría del perjuicio podría verse como una reelaboración de la teoría de la incongruencia y, por otra parte, capta una motivación de la teoría de la superioridad. ${ }^{10}$

Recordemos que la noción de incongruencia empleada en estos debates debe ser de considerable amplitud. Por ello, es sensato suponer que todo caso de perjuicio de sujetos intencionales será un caso de incongruencia. Así, si dicho perjuicio está necesariamente conectado con la comicidad - conforme a la TDP o conforme a la TFP_- también lo está la incongruencia. Veámoslo con mayor detalle. El perjuicio que el apreciador reconoce según la TDP es, al mismo tiempo, una incongruencia que ese apreciador reconoce. $\mathrm{Y}$ si, según la TFP, dicho perjuicio contribuye a provocar el divertimento,

narración no es ambigua, es comunicación bona fide). Esa estrategia no le permite explicar por qué BANCO no resulta humorístico.

${ }^{10} \mathrm{Mi}$ postura también coincide con muchas reflexiones de Morreall 2009; por ejemplo, en relación con el desapego (del que hablo más adelante), o sobre los vínculos entre el humor y el juego. Respecto de esto último, suscribo su tesis de que divertir a otros es un modo de jugar con ellos ( $c f r$. Morreall 2009, p. 34; entiendo que Morreall se refiere a divertir intencionadamente). 
entonces la incongruencia necesariamente involucrada en el perjuicio contribuye a provocar el divertimento.

Conforme a esas consideraciones, la teoría del perjuicio sería una versión prudente de la teoría de la incongruencia; una versión que no propone la incongruencia (ni por sí misma ni conjuntada con alguna otra condición identificada) como condición suficiente de la comicidad. Sólo propone, en virtud de la TDP, que cuando un apreciador experimenta divertimento cómico ante una situación, reconoce o detecta una incongruencia. $\mathrm{O}$ bien, lo que propone, en virtud de la TFP, es que la comicidad que provoca el divertimento deriva (al menos en parte) de dicha incongruencia; es esa incongruencia lo que, cuando se combina con otros factores (entre los que se incluyen los restantes rasgos que hacen de esa incongruencia un perjuicio de sujetos intencionales), el apreciador encuentra cómico.

Preguntémonos por la dirección inversa: ¿toda incongruencia conlleva perjuicio de sujetos intencionales? La respuesta es negativa, según lo atestiguan el caso ZAPATOS (este caso no incluye que alguien haya intentado meter los zapatos en la caja, y que su intención haya resultado frustrada, con el consiguiente perjuicio) y otros muchos similares. Por lo tanto, la teoría del perjuicio resulta más informativa que la versión de la teoría de la incongruencia por ella implicada; tiene mayor potencial para arrojar luz sobre lo cómico. (Desde luego, no es más informativa que teorías de la incongruencia que incluyen condiciones suficientes del humor; pero, según hemos visto, éstas son muy problemáticas.)

Excepto de forma muy indirecta, nada he dicho sobre los indicios que justifican la teoría del perjuicio. Una parte sustantiva de la justificación es que si estudiamos con atención cualquier situación presuntamente cómica, $S C_{1}$, y su previsible efecto en un apreciador, $A$, podremos identificar — quizá tras cierto trabajo de análisis de los detalles del caso- qué perjuicio reconoce $A$, si estamos considerando la versión débil, la TDP, o incluso identificar qué perjuicio es el que - junto con otros factores - le resulta cómico a $A$, si estamos considerando la versión fuerte, la TFP. En la sección siguiente trabajaré en esa línea, ilustrando la teoría con ciertos ejemplos. De momento, las conexiones descritas entre incongruencia y perjuicio nos permiten aliviar algo la tarea (que requeriría, al menos, otro artículo), apoyándonos en la literatura previa sobre el humor. En particular, cada intento de justificar que la incongruencia es una condición necesaria del humor repercute positivamente — si es un intento exitosoen favor de la teoría del perjuicio. Casos de incongruencia como 
ZAPATOS, en los cuales no hay perjuicio alguno, precisamente no se aducen cuando se quiere ilustrar la incongruencia relevante para la comicidad.

Abordaré ahora cierto rasgo de la teoría de la superioridad. Comparto la opinión mayoritaria, contraria a esa teoría. Sin embargo, una consecuencia suya resulta de especial interés aquí, pues está conectada con la teoría del perjuicio. La teoría de la superioridad implica - o al menos apoya - que en nuestro deleite cuando experimentamos divertimento cómico existe cierto grado de malicia.

Esa idea se ve reforzada por la TDP y está implicada por la TFP. Hay algo de malicia en sentir divertimento por el perjuicio de sujetos intencionales. Si queremos evitar las creencias desiderativas [wishful thinking], en principio eso no es ningún inconveniente contra la teoría del perjuicio. Además, como he anticipado, en muchas ocasiones el sujeto cuyo perjuicio provoca divertimento es el propio apreciador. Y lo que me parece más relevante es que así como el perjuicio puede ser mínimo, casi insignificante, también la malicia en la que incurrimos — según la TFP — cuando nos divertimos puede mantenerse en un nivel mínimo.

Según algunos autores, en lo que atañe a los protagonistas y los hechos de una situación cómica, adoptamos cierta actitud de desapego [disengagement] o de distanciamiento ( $c f r$. Jones 1982; Morreall 1983, cap. 8, 1997, cap. 2, 2009, pp. 53, 101-110). Comparto esa idea. Cabe especular que la relación entre desapego del apreciador y perjuicio del protagonista cómico debe ser adecuada para que resulte tolerable la malicia vinculada al divertimento. Por ejemplo, cuando la situación cómica es ficticia (incluso si involucra sujetos concretos o colectivos de sujetos existentes en el mundo real), el desapego es mayor, y aceptamos divertirnos ante el reconocimiento de perjuicios que no nos harían (o no deberían hacernos) tanta gracia si la situación cómica fuera real. ${ }^{11}$

Nos hemos aproximado a una subtemática muy frecuentada en los libros sobre humor: las relaciones entre comicidad y ética. Morreall

${ }^{11}$ Las afirmaciones de otros dos autores guardan afinidad con la teoría de la superioridad y con la teoría del perjuicio. Según Eastman (1937), todo humor concierne a cosas desplacientes [unpleasant]. Sin embargo, sitúa ese desplacer siempre en el apreciador. Conforme a la TFP, el desplacer o perjuicio relevante está en los protagonistas de la situación cómica; sólo está en el apreciador cuando la situación cómica debe incluirlo (según se dijo en la sección 3 y se ilustrará en la siguiente). Por otra parte, en la teoría de Monro (1951, cap. 19), todo lo cómico es inapropiado, aunque no viceversa. Tiendo a coincidir con esto último, pues todo perjuicio es —en cierto sentido - inapropiado. 
(1983, 1997, 2009), Cohen (1999) y Carroll (2014) dedican, cada uno de ellos en esas obras, al menos un capítulo al tema. Por razones de espacio, no profundizaré en la cuestión. Sólo quiero mencionar que, en principio, cabrían tres posicionamientos o hipótesis generales (y varias otras intermedias), análogos a posicionamientos correlativos sobre las relaciones entre arte y ética. (i) Si una situación presuntamente cómica (o una presunta obra de arte) es muy lesiva o moralmente reprobable, eso va en detrimento de su comicidad (o de su valía artística) y hace que sea menos cómica (o artísticamente valiosa). (ii) No es verdad (i), pero hay un equilibrio: cuanto más cómica sea una situación (o mayor valía artística tenga una obra) y menos lesivo (real o potencialmente) sea el perjuicio, menos reprobable moralmente será el deleite cómico (o estético) ante ella. (iii) Los aspectos éticos negativos de una situación cómica (o de una obra de arte) son separables de su cualidades cómicas (o artísticas); por muy lesivos que sean, cabe abstraerse de ellos y es moralmente aceptable apreciar — disfrutando - tanto como se pueda lo estrictamente cómico (o artístico). ${ }^{12}$

\section{Aplicación de la teoría del perjuicio: chistes y metachistes}

En el capítulo XX de la primera parte de Don Quijote de la Mancha, Sancho Panza se dispone a contarle al Quijote un relato que al final resulta ser un chiste. El chiste, llamémoslo CABRAS, tiene cierto carácter "interactivo". Tras algunos rodeos preliminares, Sancho relata las vicisitudes de un pastor que - en cierta fase del relato - concierta con un pescador cruzar un río con un ganado de trescientas cabras; pero en el único barco disponible sólo caben una persona y una cabra, por lo cual el pescador debe pasar las cabras de una en una. Sancho relata el paso de cada cabra y pide al Quijote que vaya memorizando su número, pues si llegara a descontarse no podría proseguir el relato. Pasadas varias cabras (seis, por cierto), Sancho pregunta cuántas cabras van; obtiene una respuesta airada, pues el Quijote no ha estado por esas menudencias, y sólo desea — con cierta impaciencia- que su escudero prosiga y concluya el relato. Pero éste le recuerda su

${ }^{12}$ Añado dos reflexiones. (a) Que exista analogía no implica que cada hipótesis -(i), (ii) y (iii) - tenga la misma plausibilidad en su versión relativa a lo cómico que en su versión relativa a lo artístico. (b) De esas tres posturas no se derivan inmediatamente posturas acerca de regulaciones normativas político-sociales sobre la creación y la exhibición de obras presuntamente cómicas (o artísticas). Un ejemplo: la posición (iii) es compatible con una posición restrictiva respecto de la exhibición de obras moralmente muy lesivas. 
petición y el infortunio derivado de su incumplimiento, y así finaliza el relato/chiste.

CABRAS no es un chiste típico. Pertenecería al género de los metachistes, o chistes de segundo orden, según los llama Cohen (1999, p. 4) (cfr. también Carroll 2014, p. 24). ${ }^{13}$ Enseguida mencionaré dos chistes típicos, en los cuales puede identificarse con relativa facilidad quiénes son los protagonistas cómicos de la situación narrada en tales chistes, es decir, los protagonistas a los que se ocasiona un perjuicio. Pero CABRAS y otros metachistes similares (como los dos que describiré pronto) ilustran bien la estrategia de defensa de la TDP y la TFP descrita en la sección 3. La situación, $S C_{1}$, "narrada" en el chiste no es una situación realmente cómica. En efecto, no hay perjuicio relevante contra el pastor, sus cabras o el pescador. La situación cómica, $S C_{2}$, es la situación comunicativa que incluye al emisor, Sancho, y al apreciador-audiencia, Alonso Quijano. Es éste quien ve perjudicada su expectativa de entretenerse escuchando un relato ameno.

He aquí dos chistes prototípicos, muy diferentes de CABRAS.

DESPISTE

- Mamá, mamá, en el cole me llaman despistado.

—Anda, niño, vete a tu casa... (cfr. Vigara Tauste 1994, p. 84).

\section{GOLPES}

Dos gamberros se aburren en una sala de cine. G1 reta a G2:

- Ves aquel calvo de allá abajo, mirando la peli tan confiado. ¿Te apuesto diez euros a que voy y sin mediar palabra le arreo un guantazo bien dado, con la mano abierta?

G2 acepta la apuesta. G1 va hasta CC, le propina el guantazo y dice:

—QQué sorpresa, Ambrosio! Me alegro de encontrarte por aquí.

CC, muy quejoso, protesta que él no es Ambrosio ni conoce de nada a G1. Éste se disculpa y vuelve al asiento. G1 insiste ante G2:

_ ¿Otros 10 euros a que le doy otra vez?

La escena se repite. CC, dolorido, cambia de sitio y va a sentarse tres filas más alejado. Gl reitera la apuesta. Tras el sonoro guantazo, esta vez Gl le dice a CC:

${ }^{13}$ En rigor, eso no es exacto. Los metachistes explotan la práctica comunicativa preexistente de contar chistes. Pero Sancho no había anunciado que iba a contar un chiste, sino un relato (a petición del propio Quijote). Podemos prescindir de ese detalle e imaginar CABRAS contado anunciando que va a contarse un chiste. Por otro lado, no todos los metachistes son semejantes a CABRAS. Cohen (1999, p. 5) expone un metachiste que consiste en un chiste que contiene otro chiste. 
- No te lo vas a creer, Ambrosio. Te he estado confundiendo todo el rato con un calvo capullo de allá atrás que es igualito que tú.

Es obvio qué perjuicio relevante sufren los protagonistas de las situaciones cómicas correspondientes a esos dos chistes. Como quizá ocurre con todos los chistes, el desenlace de DESPISTE y GOLPES provoca sorpresa en la audiencia, y por ello - según indicamos en la sección 3- las expectativas del apreciador-audiencia se ven trastocadas, con el consiguiente perjuicio (insignificante, aunque real). Pero no es ése el perjuicio más relevante; éste se encuentra en la situación cómica narrada, no en la situación comunicativa global.

Vayamos con otros dos metachistes, que explotan la situación comunicativa, la situación que consiste en contar el chiste.

\section{GLUGLUITOS}

El emisor-narrador, $E$, narra la marcha de un pequeño grupo de individuos que va diciendo:

- Somos los glugluitos, somos los glugluitos.

El grupo se hace cada vez más numeroso, siempre con la misma frase. $E$ alarga la narración tanto como le parece conveniente. Finalmente, $E$ cuenta que el grupo, ya multitudinario, se dirige a la playa. Allí se adentran poco a poco en el mar, y la frase es ahora parcialmente onomatopéyica:

- Somos los glugluglu...

FAMILIA

_ ¿En qué se parece una cueva a una piedra y a la familia?

-No sé.

-En que la cueva está húmeda y la piedra u me da u no me da.

— ¿Y la familia? - Muy bien, gracias.

En GLUGLUITOS no hay por qué suponer que los protagonistas del chiste, los glugluitos, sufran perjuicio de ningún tipo (no se da a entender que les sorprenda su inmersión, por ejemplo). Quien queda sorprendido y frustrado en su expectativa de oír un chiste estándar es el apreciador-audiencia. FAMILIA procede de Vigara Tauste (1994, p. 82), que denomina chistes-con-cómplice a chistes con las características de CABRAS, GLUGLUITOS y FAMILIA. En realidad, FAMILIA es una suerte de chiste mixto, pues el breve comentario sobre "cueva" y "piedra" ya constituye un chiste por sí mismo, basado en un juego de palabras. Llamaré CUEVA a ese chiste componente de FAMILIA, que consiste en las frases: "¿En qué se parece una cueva a una piedra? En que la cueva 
está húmeda y la piedra $u$ me da u no me da." A mi juicio, también el análisis correcto de CUEVA — y otros chistes similares, sin protagonistas concretos - requiere (aunque no tan claramente como CABRAS, GLUGLUITOS y FAMILIA) imaginar que la situación cómica incluye al apreciador-audiencia cuyas expectativas resultan de cierta manera frustradas. Sobre FAmilia, Vigara Tauste afirma "el cómplice es el receptor [el apreciador-audiencia] que, sin saberlo, cuajará definitivamente el chiste (doble motivo para reírse: del chiste y de sí mismo)" (Vigara Tauste 1994, p. 82). Me parece una reflexión certera, excepto porque - según sugiere mi comentario sobre CUEVA - ambos motivos para reírse serían motivos para reírse de sí mismo, aunque las expectativas frustradas son distintas.

Es muy natural considerar que, en CABRAS y en GLUGLUITOS, la situación cómica propiamente dicha no está en lo narrado, sino que es la situación comunicativa global, que incluye al apreciadoraudiencia. Y es fácil identificar el perjuicio de éste, pues se relaciona con la frustración de sus expectativas. En otras palabras, no es una estrategia ad hoc defender la TFP ante esos potenciales contraejemplos señalando que la situación presuntamente cómica desnuda (en el sentido que definimos en la sección 3) no es realmente cómica, mientras que sí lo es la situación global que incluye al apreciador. (Recordemos que, a diferencia de lo que le sucede al Quijote, nuestro divertimento final suele contrarrestar el perjuicio que nos ocasiona oír ese tipo de metachistes. $)^{14}$

Con respecto a los chistes, la viabilidad de la teoría del perjuicio —en su versión fuerte (TFP) — dependerá de que resulte también natural o poco forzado aplicar esa estrategia a otros muchísimos casos en los cuales la situación narrada, desnuda, no parezca contener perjuicio alguno de sujetos intencionales. Mi defensa de la TFP lleva asociada esa promesa teorética. Un gran número de chistes no ilustran la TFP tan fácilmente como los chistes prototípicos DESPISTE

\footnotetext{
${ }^{14}$ Podemos identificar al menos un punto en que la teoría del perjuicio tiene consecuencias constrastables si usamos tres supuestos auxiliares (uno de ellos vinculado a la propia teoría): (i) preferimos reírnos de los perjuicios ajenos que de los propios; (ii) al contar un chiste buscamos la risa de la audiencia; (iii) tenemos conocimiento implícito - o al menos creencia implícita - de la TFP. Combinada con (i), (ii) y (iii), la TFP prevé que la frecuencia relativa de casos en que metachistes como CABRAS, GLUGLUITOS y FAMILIA se contarán ante audiencias colectivas es mayor que la frecuencia relativa análoga correspondiente a chistes típicos como DESPISTE y GOLPES. El apreciador del primer tipo de chistes no sólo se ríe de sí mismo, sino también del resto de apreciadores que constituyen la audiencia y comparten su perjuicio.
} 
y GOLPES, pero tampoco son claros ejemplos de metachistes paradigmáticos como CABRAS, GLUGLUITOS y FAMILIA. La defensa pormenorizada de la TFP acarrearía, ante cada chiste que se presentara como presunto contraejemplo, poder mostrar que sí contiene (quizá pese a las apariencias iniciales) protagonistas cómicos perjudicados, o que no resulta ad hoc sostener que la situación cómica debe incluir al apreciador-audiencia. Ejemplos de lo segundo son CUEVA (conforme al análisis que he propuesto), así como CAFÉ: "Entra un tipo en un café y... chaaf". Comprender CAFÉ no requiere atribuir un perjuicio a ese sujeto (quizá — como los protagonistas de GLUGLUITOS - ya sabe dónde se mete al "entrar" en ese "café"); pero es sensato (no suena forzado, no suena ad hoc) considerar que lo que nos divierte es nuestra propia reacción ante el desenlace del chiste.

En cuanto al resto de situaciones cómicas (diferentes de los chistes), la perspectiva general es la misma. La viabilidad de la TFP está vinculada a la promesa descrita. El compromiso con la TFP requiere suponer que, para cada situación presuntamente cómica, podrían identificarse sujetos cómicos (concretos o colectivos) perjudicados, o bien resultará aceptable sugerir que el apreciador debe estar incluido en la situación realmente cómica. Profundizar en esa tarea sobrepasa los límites de espacio que me he marcado en este trabajo.

\section{Conclusiones}

He presentado y explorado una determinada teoría sobre la comicidad que vincula lo cómico con el perjuicio de sujetos intencionales; o con el perjuicio, simplemente, si todo perjuicio lo es siempre de sujetos intencionales.

Como sucede con otros enfoques teóricos contemporáneos acerca del humor, he invocado el concepto de divertimento o regocijo cómico: el estado mental que lo cómico tiende a provocar. La teoría del perjuicio se desglosa en una versión débil y otra fuerte. La tesis débil, TDP, establece que cuando se experimenta divertimento cómico ante una situación, el apreciador (el sujeto que siente ese divertimento) reconoce o detecta un perjuicio en sujetos intencionales. La tesis fuerte, TFP, establece además que la comicidad que provoca el divertimento deriva (al menos en parte) de dicho perjuicio; el perjuicio es aquello que, cuando se combina con otros factores, el apreciador encuentra cómico.

Es usual clasificar, en tres categorías, las principales concepciones filosóficas sobre el humor propuestas a lo largo de la historia: teorías de la superioridad, teorías de la incongruencia y teorías del alivio. 
Se considera - en general- que las teorías de la superioridad y las teorías del alivio son bastante problemáticas. En épocas relativamente recientes, muchos especialistas han defendido versiones de la teoría de la incongruencia. Casi todos esos enfoques, también en sus versiones contemporáneas, aspiran a ofrecer condiciones necesarias y conjuntamente suficientes de lo humorístico. Sin embargo, según he resaltado, se les plantean contraejemplos; sobre todo contraejemplos a su pretensión de establecer condiciones suficientes del humor (sucede eso, por ejemplo, con las propuestas de Clark, Raskin y Carroll). La teoría del perjuicio no es tan ambiciosa: establece sólo condiciones necesarias de la comicidad, pero no condiciones suficientes.

No obstante, para la exposición y clarificación de la teoría del perjuicio es aconsejable compararla con otras concepciones del humor. En concreto, mi propuesta puede verse como una variante de la teoría de la incongruencia, pues todo perjuicio conlleva una incongruencia. Además, se conecta con la teoría de la superioridad: un posible atractivo de esa teoría (implica la existencia de cierto nivel de malicia en el apreciador) queda explicado por la teoría del perjuicio, pues también ésta - en su versión fuerte, TFP — tiene dicha consecuencia.

La malicia en juego puede ser de menor calibre. Cuestiones sobre el equilibrio entre el nivel de malicia y el apropiado deleite ante lo cómico - las cuales conducen a las relaciones entre humor y éticase comentan brevemente en la sección 5 .

He recurrido a un contraste entre comicidad y valor artístico, con vistas a clarificar algunos rasgos de mi teoría. Aunque hay intencionalidad en el artista y en el apreciador de su obra, parece inteligible aceptar que haya situaciones representadas (en una obra de arte) desprovistas de sujetos intencionales. Según la TFP, no existen situaciones cómicas sin sujetos intencionales (concretos o colectivos, reales o imaginados).

Un punto clave en mi defensa de la teoría del perjuicio es una estrategia general para hacer frente a presuntos contraejemplos. He caracterizado una situación cómica desnuda como aquella situación cómica que no incluye al apreciador de la misma. La tesis TFP implica que no existen situaciones cómicas desnudas en las cuales no haya perjuicio de ningún sujeto intencional. Si $S_{1}$ es un presunto contraejemplo, la estrategia de respuesta propone - en general- que la situación realmente cómica es $S_{2}$, una situación global que incluye $S_{1}$, al apreciador y un perjuicio que éste ha sufrido. Ilustro la estrategia comentando casos de ciertos metachistes, cuya apropiada descripción 
permite decir que la situación cómica incorpora, en efecto, algún perjuicio ocasionado al apreciador-audiencia. ${ }^{15}$

\section{BIBLIOGRAFÍA}

Carroll, N., 2014, Humour: A Very Short Introduction, Oxford University Press, Oxford.

Casablancas Domingo, B., 2000, El humor en la música. Broma, parodia e ironía, Reichenberger, Berlín.

Clark, M., 1970, "Humor and Incongruity", Philosophy, vol. 45, no. 171, pp. 20-32; reimpreso en Morreall 1987, pp. 139-155 (a cuya paginación remito en este texto).

Cohen, T., 1999, Jokes: Philosophical Thoughts on Joking Matters, The University of Chicago Press, Chicago.

Eastman, M., 1937, Enjoyment of Laughter, Hamish Hamilton, Londres.

Grice, H.P., 1975, "Logic and Conversation", en P. Cole y J.L. Morgan, Syntax and Semantics, vol. 3, Speech Acts, Academic Press, Nueva York, pp. 41-58; reimpreso en Studies in the Ways of Words, Harvard University Press, Cambridge, Mass., 1989, pp. 22-40 (a cuya paginación remito en este texto).

Hutcheson, F., 1750, Reflections upon Laughter, R. Urie, Glasgow.

Jones, P., 1982, "Laughter", Proceedings of the Aristotelian Society, vol. supl. 56, pp. 213-228.

Martin, M.W., 1983, "Humor and the Aesthetic Enjoyment of Incongruities", British Journal of Aesthetics, vol. 23, no. 1, pp. 74-85; reimpreso en Morreall 1987, pp. 172-186 (a cuya paginación remito en este texto).

Monro, D.H., 1951, Argument of Laughter, Melbourne University Press, Melbourne.

Morreall, J., 2009, Comic Relief: A Comprehensive Philosophy of Humor, Wiley-Blackwell, Malden.

——, 1997, Humor Works, Human Resource Development Press, Amherst.

—_ 1983, Taking Laughter Seriously, State University of New York Press, Albany.

- (comp.), 1987, The Philosophy of Laughter and Humor, State University of New York Press, Albany.

${ }^{15}$ Estoy en deuda con Agustín Vicente por comentar conmigo algunas hipótesis centrales contenidas en este trabajo. Financiación: Proyectos "Objetividadsubjetividad en el conocimiento y en la representación singular" (FFI2015-63892-P), (MINECO, AEI/FEDER, UE) y "Perspectival Thoughts and Facts: New Questions" (FFI2016-81858-REDC; Red CONSOLIDER 2016, Acción de Dinamización, Red de Excelencia) (Gobierno de España/Unión Europea). Grupo de investigación consolidado LOGOS (2017SGR63), AGAUR (Gobierno catalán). 
Pérez Otero, M., 2009, "La regla de la aseveración y las implicaturas argumentativas", Theoria. An International Journal for Theory, History and Foundations of Science, vol. 24, no. 1, pp. 63-81.

Raskin, V., 1984, Semantic Mechanisms of Humor, Reidel, Dordrecht.

Scruton, R., 1982, "Laughter", Proceedings of the Aristotelian Society, vol. supl. 56, pp. 197-212; reimpreso en Morreall 1987, pp. 156-171 (a cuya paginación remito en este texto).

Vigara Tauste, A.M., 1994, El chiste y la comunicación lúdica: lenguaje y praxis, Ediciones Libertarias, Madrid.

Recibido el 3 de enero de 2018; revisado el 6 de junio de 2018; aceptado el 25 de julio de 2018. 